\title{
Finite Element Analysis of the Dynamic Contact Stress of Cycloid Gear of RV Reducer
}

\author{
YAO Can Jiang ${ }^{1, a^{*}}$, WEI Ling Hui ${ }^{2, b}$ \\ ${ }^{1,2}$ North China University of Technology Beijing 100144, China \\ a962860830@qq.com, ’weilinghui@126.com
}

Keywords: parametric model; gear contact strength; simulation analysis

Abstract. Regarding the RV speed reducer with the transmission of the cycloid gear as the research object,using the powerful parametric design function of Pro/Engineer5.0 is to accurately create the parametric model of the internal gear and the pin gear of the RV reducer. Then making using of ANSYS Workbench15.0 to imitate the transmission process of analyzes contact strength of cycloid gear between them, which provides a powerful reference for the analysis and evaluation.

\section{Introduction}

$\mathrm{RV}$ (Rotate Vector) is a new speed reducer which is developed with cycloid gear reducer. And it is characterized by strong bearing capacity, high efficiency, small volume, light quality and compact construction, which is widely used in aerospace field, industry robots field. And cycloid gear is used as its main component. Because of the complexity of carrying capacity, itis very difficult to confirm its relatively precise distribution regularity of stress by the traditional accounting ways. With the help of some existing finite element software to study the gears' deformations of bearing and stress, modern design approaches not only obtain stress values, but can make the distribution areas clear to make the pin gear system gain better optimal design, which can promote the rate of success of physical sample tests.

\section{The transmission theory of cycloid gearing planetary}

As show in the Figure 1, when the rolling circle with $r_{g}$ is circumscribed to the base circle with $r_{b c}$, and the rolling circle is rolling on the base circle, the locus of arbitrary point $\mathrm{A}$ of the rolling circle, $A A_{1} A_{2} A_{3} A_{4}$, is epicycloids. The locus of point $\mathrm{B}$ in the rolling circle, $B B_{1} B_{2} B_{3} B_{4}$,

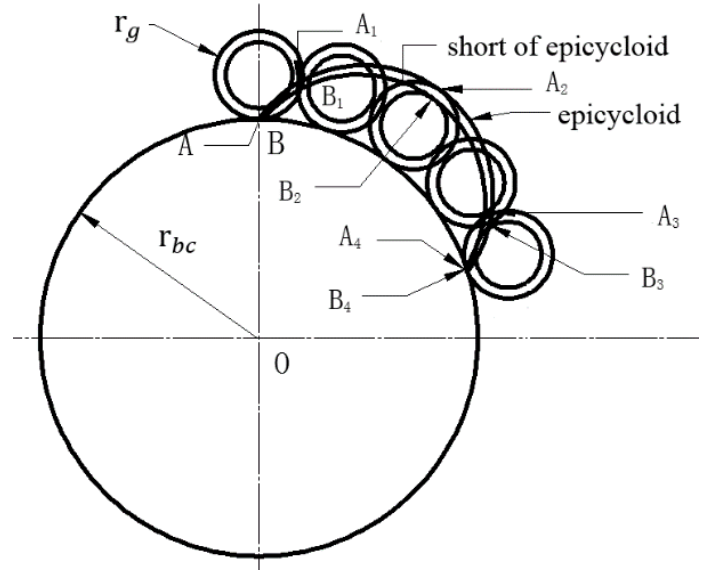

Fig.1 The forming principle of epicycloid figure

\section{RV speed reducer cycloid gear modeling}

Owing to the relative complexity of the tooth profile curve of cycloid gear, based on the weak function of modeling of the finite element software ANSYS Workbench15.0, the paper use Pro/Engineer5.0 to create solid model of cycloid gear. According to references, the cycloid gear 
equation in the coordinate system as follows:

$a=b^{*} t$

$m=\frac{\left(k * \sin \left(\left(z_{g}+1\right) * a\right)-\sin (a)\right)}{\sqrt{\left(1+k^{2}-2 * k * \cos \left(z_{g} * a\right)\right)}}$

$n=\frac{\left(-k * \cos \left(\left(z_{g}+1\right) * a\right)+\cos (a)\right)}{\sqrt{\left(1+k^{2}-2 * k^{*} \cos \left(z_{g}^{*} a\right)\right)}}$

$x=r_{z} * \sin (a)-e * \sin \left(\left(z_{g}+1\right) * a\right)+d z * m$

$y=r_{z} * \cos (a)-e^{*} \cos \left(\left(z_{g}+1\right) * a\right)-d z^{*} m z=0$

In the equation, $z_{g}$ as the number of teeth of the cycloid gear, $k$ as the curtate ratio, $r_{z}$ as the radius of distribution circles of pin gear, $e$ eccentricity, $t$ as system variable of $0 \sim 1$

The paper takes reducer RV-4OE as example and use GCr15, 208GPa as elasticity modulus, and poisson ratio is 0.3 . The major parameter is shown in the Table 1:

Table 1.The main parameters of cycloid gear table

\begin{tabular}{cc}
\hline Parameter types & Numerical \\
\hline Needle teeth & 40 \\
Cycloid gear width & $10 \mathrm{~mm}$ \\
Eccentricity & $1.5 \mathrm{~mm}$ \\
The central circle diameter of pin gear & $132 \mathrm{~mm}$ \\
Needle tooth diameter & $6 \mathrm{~mm}$ \\
Turning arm bearing hole diameter & $29 \mathrm{~mm}$ \\
The input shaft hole diameter & $32 \mathrm{~mm}$ \\
Turning arm bearing diameter distribution & $73.5 \mathrm{~mm}$ \\
\hline
\end{tabular}

The main parameters of cycloid gear tooth radius, (that is, the pin gear radius, the pin gear central circle radius, cycloid gear teeth, eccentricity, etc.) is inputted to Pro/Engineer5.0, driving the "relationship" menu model size, inputting the cycloid tooth profile curve equation under rectangular coordinate system to generate the cycloid gear tooth profile curve with a notepad, as shown in figure 2 . Through orders like stretch and cut to create solid model of cycloid gear is shown in figure 3 . And assemble the cycloid gear geometry solid model and the corresponding pin tooth, ensure do not produce interference after assembling, after import ANSYS Workbench15.0 platform with the transient dynamic analysis for the next step. The RV reducer cycloid gear and pin gear assembly as shown in figure 4.

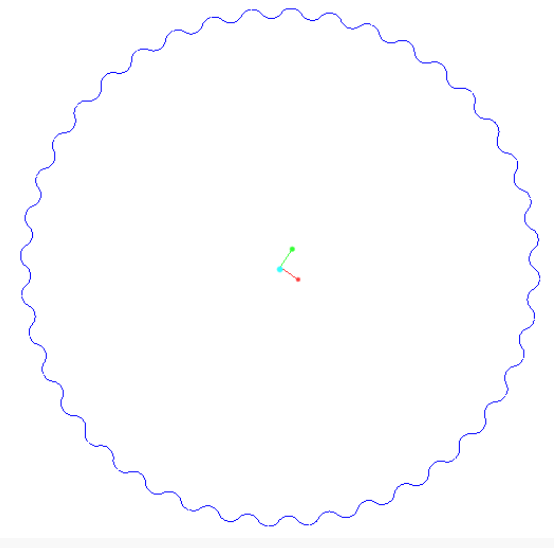

Fig. 2 Cycloid gear tooth profile curve

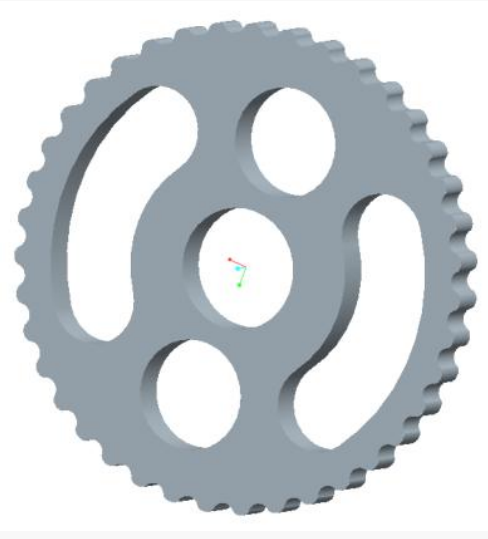

Fig. 3 Cycloid gear entity model diagram 


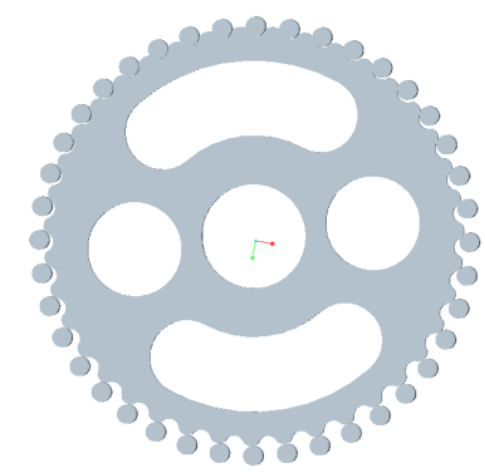

Fig. 4 Cycloidal needle wheel and gear assembly diagram

\section{RV speed reducer cycloid gear dynamic contact finite element analysis}

The basic idea of finite element analysis is to divide the solution domain of into several units, and through boundary nodes connecting to a combination, and then using the assumption of approximate function within each unit to shard to express the whole solution domain to solve the unknown field variables $^{[4-6]}$. According to the actual transmission of cycloid gear carrying capacity to analyze the stress field of cycloid gear finite element simulation, to determine the maximum stress value of gear and the stress distribution, and analyze of the gear structure parameters and if material performance meets the requirement, and provide the basis for the optimization of gear.

Parameter setting and meshing

By using the software seamless interface of Pro/ Engineer5.0 software and ANSYSWorkbench15.0, the level 1 of transmission gear train of $3 \mathrm{~d}$ model is directly inducted into ANSYSWorkbench15.0 platform to do the transient dynamic analysis.

Definite isotropic material, material elastic modulus as $E=2.08 \times 10^{11} \mathrm{~Pa}$, poisson's ratio as $\mu=0.3$, density as $7850 \mathrm{~kg} / \mathrm{m}^{3}$.

For cycloidal gear and pin gear in the transmission process of kinetic analysis, if we only set up one or two tooth surface contact, the contact area will be less, which is not enough to reflect the actual situation. Therefore, we should choose inner surface of pin gear and the cycloid gear outer contour surface of contact area, and then in the Settings panel, choose the contact types for the "Frictinless", the other set keep default.

After contact settings, because the relationship between cycloid gear and pin gear approximation for rotation, therefore we need to define the relationship between the cycloid gear and pin tooth articulated. The cycloid gear is to be defined as the rotation vice, in the settings panel, setting the "Connection Type" to "Body - Ground", and in the "Type" selecting "Revolute.

In setting body scanning method and marginal control function method was carried out on the gear meshing ${ }^{[8]}$. In order to guarantee the precision and accuracy of the simulation, the gear contact area has the local refinement, generate 249861 meshes, 1147385 nodes. The division of gridding as shown in figure 5 , and 6.

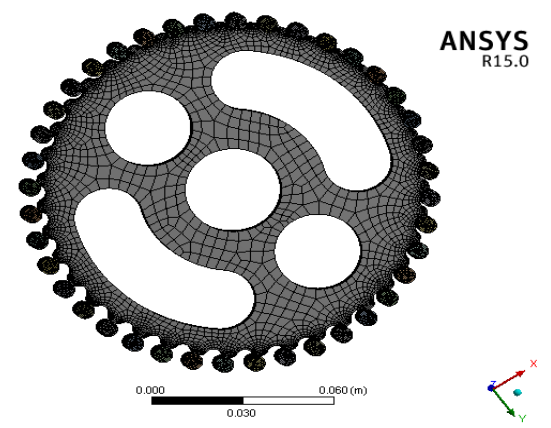

Fig. 5 Cycloidal needle wheel and gear mesh

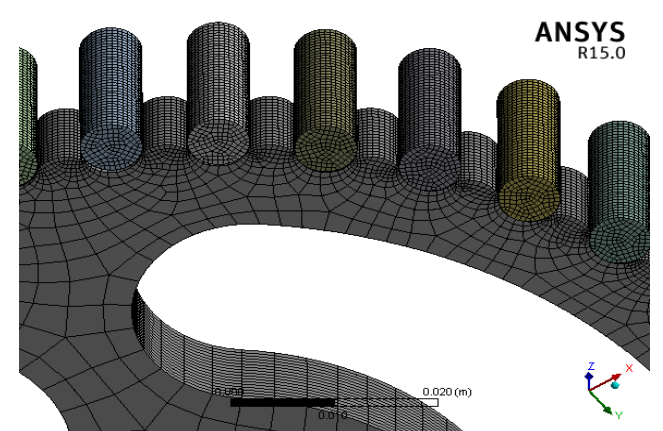

Fig.6 Cycloidal needle wheel and tooth local grid 


\section{Applied load and constraint conditions}

Because of the moment cycloid gear and pin gear meshing, cycloid gear has rotation relative to the pin. There are also a small mobile at the same time, so the torque is adopted instead of the effect on single tooth force loading method ${ }^{[9]}$, then selecting the input shaft hole adding rotating Load, (Joint Load), of which the type is set to the moment; Input table 2 in the magnitude of the input shaft hole under the condition of rotational torque; Similarly, add input shaft hole of the rotating angular velocity, the final choice of cycloid gear and pin gear contact tooth surface to add moving load, (Joint Load), in which the Type set to below, enter a tiny displacement values in magnitude. The solution under various operating conditions has equivalent stress nephogram.

Table 2. Several parameters in the cases of the RV reducer

\begin{tabular}{ccc}
\hline Working condition of type & Output speed $(r / \min )$ & Output torque $(N \bullet m)$ \\
\hline 1 & 5 & 280 \\
2 & 10 & 226.5 \\
3 & 15 & 200 \\
4 & 20 & 183 \\
5 & 25 & 177.5 \\
6 & 30 & 169.5 \\
7 & 35 & 165 \\
\hline
\end{tabular}

When the RV reducer output torque is $280^{N \bullet m}$, and the output speed of $5^{r / m i n}$, under the condition of cycloid gear and pin gear meshing transient dynamics analysis of the results as shown in figure 7,8

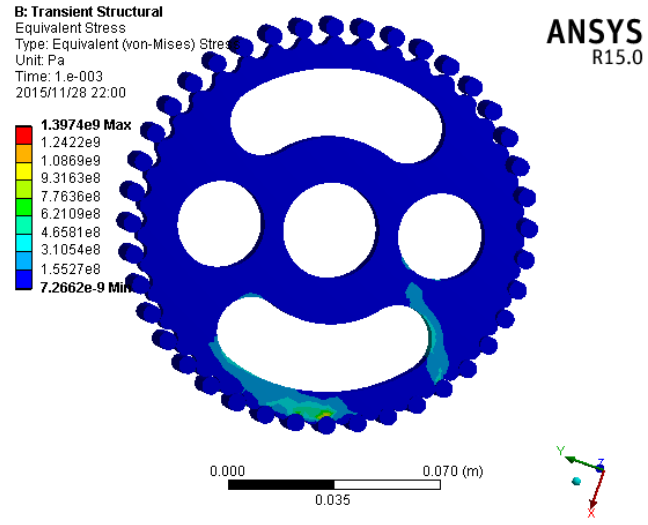

Fig.7. Working condition of cycloid gear train one stress nephogram

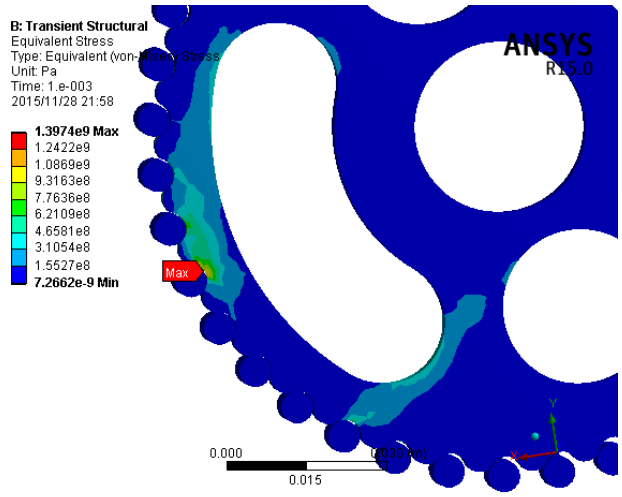

Fig 8. Cycloid gear train working condition of the local stress nephogram of one

When the input power of the RV reducer is $226.5^{N} \bullet \mathrm{m}$, and the output speed is $10^{r / \mathrm{min}}$, under the condition of cycloid gear and pin tooth transient dynamics analysis of the results as shown in figure $9,10$.

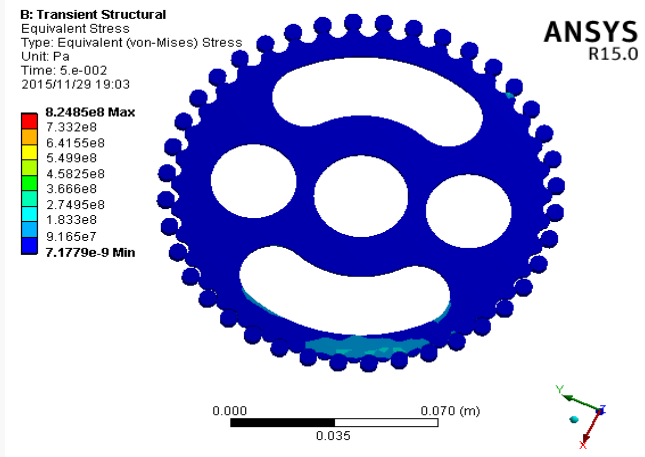

Fig. 9 Working condition of cycloid gear train five stress nephogram

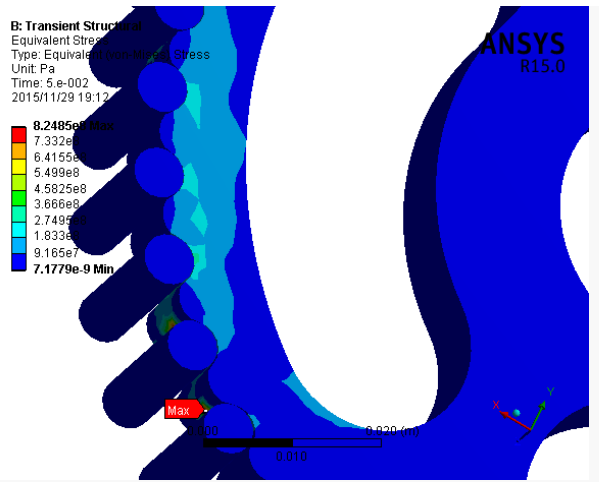

Fig 10. Cycloid gear train working condition of the local stress nephogram of five 
The calculation results and the post-processing

By using ANSYS Workbench15.0 transient dynamics to analyze, calculate all kinds of cycloid gear and pin gear meshing process under the condition of maximum stress of as shown in table 3 .

From figure 7, 8, 9, 10 stress distribution chart, we can see that stress of cycloid gear and pin gear contact area is the largest. In the contacting place, cycloid gear and the output forms a stress concentration phenomenon, dangerous parts of the gear at contact.

As the literature ${ }^{[10]}$, the maximum stress value of finite element simulation analysis is less than the allowable contact stress of GCr15, so it satisfies the requirement of contact strength.

Table 3. Simulation calculating contact stress under different working conditions

\begin{tabular}{ccc}
\hline output speed $(r / \min )$ & output torque $(N \bullet m)$ & maximum contact stress $(M P a)$ \\
\hline 5 & 280 & 1397.4 \\
10 & 226.5 & 1132.7 \\
15 & 200 & 947.27 \\
20 & 183 & 892.53 \\
25 & 177.5 & 824.85 \\
30 & 169.5 & 788.32 \\
35 & 165 & 729.18 \\
\hline
\end{tabular}

The table 3 shows that the first condition of planetary gear contact stress is the largest, prone to gear failure, so the safety factor analysis is necessary. In ANSYS workbench 15.0 business environment, it provides a based on the maximum equivalent stress tools (Max Equivalent stress), safety coefficient of force situation. According to the working condition of the parts, and generating working condition of the safety factor, so the most easily broken is in gear meshing area of damage. The safety factor of the working condition of the RV reducer cycloid gear train in a cloud is as shown in figure 11.

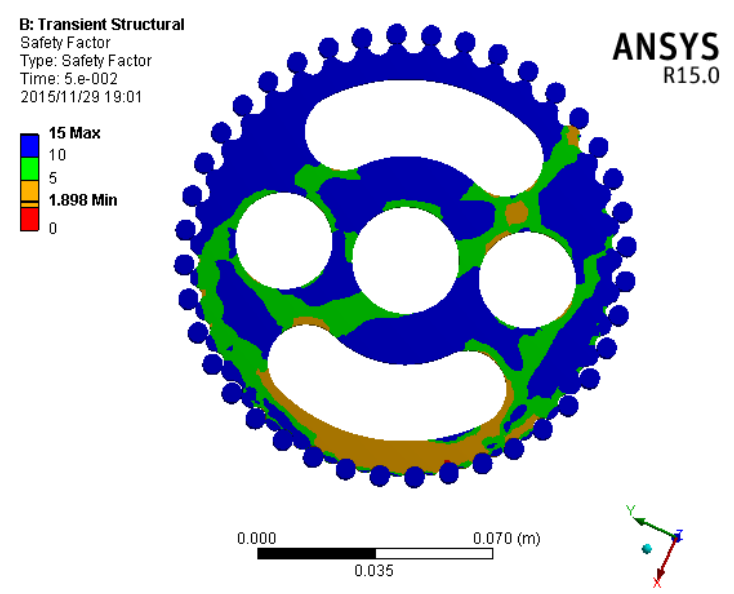

Fig. 11 Cycloid gear train the safety factor of the working condition of a cloud

Working condition of the figure 11 shows that a state of cycloid gear train minimum safety factor of 1.898 is greater than 1 , shows that under the condition of stress of the cycloid gear won't reach the yield limit.

\section{Conclusion}

(1) By contacting simulation analysis, it can truly show that the actual stress condition of cycloid gear with teeth, make stress distribution clear, avoid the the complexity of searching parameters of traditional theory and calculation, which provides technical support for optimal design of cycloid gear. 
(2) In the process of ANSYS Workbench15.0 finite element analysis of cycloid gear contacting pin gear, the accuracy and credibility of simulation results depends on the correct modeling, the reasonable control of the grid and to accurately grasp the actual working condition.

(3) The use of Pro/Engineer5.0 with ANSYS Workbench15.0 software to complete the project analysis and project design optimization method has certain reference value in engineering design.

\section{References}

[1] Hao Xu,Mechanical Design Manual [M].Beijing:Mechanical Industry Press, 1991.

[2] Xiaolu Zhu,Mechanical Design Manual [M].Beijing:Electronic Industry Press,2007,07,666-668.

[3] Linshan Han,Yunfu Dong and Hao Li,The $2 \mathrm{k}$ - V Type Reducer with Solidworks 3 D Parametric Design of the Cycloidal Wheel[J],Coal Mine Machinery,2012,2,106-109.

[4] Jianfeng Li and Yingbin Jian,Lying Pillow Needle Cycloid Transmission Force Analysis of Tooth Structure[J],Mechanical Design and Manufacturing,2014,10,49-52.

[5] Liang Zhao,Peng Zhang and Yuhua Zhang,Cycloid Steel Ball Planetary Gear Meshing Pair Load Error[J],Mechanical Transmission,2013,3,11-14.

[6] Xiaojun Liu,Yongqiang Shi and Wei Wang,Based on ANSYS Workbench of Compound Gear Pump Gear Meshing Finite Element Analysis[J],Coal Mine Machinery,2009,5,52-54.

[7] Pingping Duanmu,Liangmo Wang and Hanguan Xia,A Dynamic Contact Simulation of Differential Gear and Fatigue Analysis[J],Journal of Applied Mechanics,2014,4,595-600.

[8] Zhiheng Zhai,Zhenghao Ge and Kai Zhang,Involute Gear Nonlinear Contact Problem of Finite Element Analysis[J],Coal Mine Machinery,2012,1,94-96.

[9] Di Wu and Youzhen Zhang,The Many Teeth Difference Cycloid Gear Based on ANSYS Finite Element Analysis[J],Mechanical Design,2009,5,40-42.

[10] Datong Qin and Liyang Xie,Modern Mechanical Design Manual[M].Beijing:Chemical Industry $\mathrm{P}$ 